\title{
Tonal Alignment in Three Varieties of Hiberno-English
}

\author{
Raya Kalaldeh, Amelie Dorn, and Ailbhe Ní Chasaide \\ Phonetics and Speech Science Laboratory, \\ Centre for Language and Communication Studies, Trinity College Dublin \\ kalalder@tcd.ie, dorna@tcd.ie, anichsidetcd.ie
}

\begin{abstract}
This pilot study investigates the tonal alignment of pre-nuclear $(\mathrm{PN})$ and nuclear $(\mathrm{N})$ accents in three Hiberno-English (HE) regional varieties: Dublin, Drogheda, and Donegal English. The peak alignment is investigated as a function of the number of unstressed syllables before PN and after N. Dublin and Drogheda English appear to a have fixed peak alignment in both nuclear and pre-nuclear conditions. Donegal English, however, shows a drift in peak alignment in nuclear and prenuclear conditions. Findings also show that the peak is located earlier in nuclear and later in pre-nuclear conditions across the three dialects.

Index Terms: peak alignment, Hiberno-English, nuclear and pre-nuclear accents
\end{abstract}

\section{Introduction}

This paper examines the peak alignment of three regionally different varieties of Hiberno-English, see Figure 1. The investigation of tonal alignment across regional varieties of $\mathrm{HE}$ aims to contribute to the description and understanding of prosodic differences between dialects. Many recent studies investigate the peak alignment of different European languages, and also that of language varieties [1-5]. Several factors are reported to influence peak alignment: vowel-length, syllable structure or the position of the accented syllable in the intonational phrase. Peaks in Standard Scottish English were found to be consistently later than those in RP. In Dutch the peak is aligned during the accented vowel if the vowel is long and during the following consonant if the vowel is short [3].

Recent work on the prosody of Irish (Gaelic) shows that Irish dialects can differ significantly in their peak alignment not only across, but also within dialects. In the Connemara dialect of Cois Fharraige the peak is fixed in nuclear and prenuclear conditions. In the Ulster dialect of Gaoth Dhobair, on the other hand, the peak shifts rightwards in pre-nuclear and nuclear positions as a function of the number of unstressed syllables [4]. Moreover, differences in peak alignment within dialects of Irish have been reported [5]. The three Connaught dialects of Irish (Mayo, Cois Fharraige and Inis Oirr) show similar tonal patterns. Nonetheless, the timing of peak alignment is extremely variable in Mayo, relatively variable in Inis Oirr and fixed in Cois Fharraige.

The present study is prompted partly by the absence of phonetic studies on HE varieties. Studies on HE have been very scarce with the majority carried out on the rather distinctive and diverse varieties of Northern HE [6,7]. To-date most phonetic analyses concentrate on segmental features [68]. Studies on the intonation of HE have been rare, but there is an increasing interest in this aspect [9-13].

HE has been strongly influenced by Irish. There are many studies that trace phonological features in present day HE to Irish $[14,15]$. Southern HE, for example, is characterised by a rounded and close realisation of the STRUT vowel $[\theta]$ or $[\gamma$, which is very similar to the Irish vowel [ $\gamma]$ [16]. In his study of the HE dialect of North Roscommon, Henry [15] mentions that the inherent aspect of palatalized versus non-palatalized consonants of Irish is reflected in the consonantal system of the dialect. He also suggests that the slow tempo and the lengthening of final consonants after short vowels in stressed monosyllables are typical of North Connaught and South Donegal Irish. It would be interesting to investigate not only segmental but also prosodic features of HE. Thus, the findings of this study will lend themselves to comparison with Irish as well as English varieties.

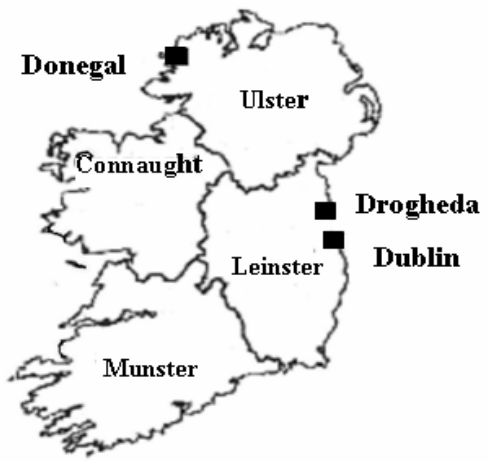

Figure 1: Map showing the location of the three dialects investigated.

Dublin English is a southern variety of HE. The Drogheda dialect lies at the furthest north-east end of the boundary zone separating Northern HE and Southern HE [6]. Declaratives in Dublin and Drogheda English are characterised by predominantly $\mathrm{H}^{*} \mathrm{~L}$ pre-nuclear and nuclear accents. Donegal English is a Northern variety of HE. It shows broad similarities to both Belfast English and Donegal Irish [13]. Thus, the distinctive $\left(\mathrm{L}^{*} \mathrm{H}\right)$ pitch accent of Donegal English in initial pre-nuclear and nuclear accents stands in contrast to the other two varieties. Therefore the accent types, which are the focus of this paper, are both $\mathrm{H}^{*} \mathrm{~L}$ (Dublin, Drogheda) and $\mathrm{L} * \mathrm{H}$ (Donegal) pre-nuclear and nuclear accents in declarative statements. Tonal alignment of the main target tones $\left(\mathrm{H}^{*}\right.$ in $\mathrm{H}^{*} \mathrm{~L}$ and $\mathrm{L}^{*}$ in $\left.\mathrm{L}^{*} \mathrm{H}\right)$ is investigated. Furthermore, the distance between $\mathrm{L}^{*}$ and $\mathrm{H}$ (in $\mathrm{L}^{*} \mathrm{H}$ ) in Donegal English is examined. It should be noted that the term 'peak' used in this paper refers to either $\mathrm{H}^{*}$ in $\mathrm{H}^{*} \mathrm{~L}$ or to the trailing tone $\mathrm{H}$ in $\mathrm{L} * \mathrm{H}$. 


\section{Methods and Materials}

\subsection{Materials}

The data used in this study is part of a larger corpus recorded for alignment studies in Hiberno-English. Four sentences are controlled for the number of unstressed syllables following the nuclear accents, varying from zero (N0) to three (N3). Another four sentences are controlled for the number of unstressed syllables before the pre-nuclear accents, varying from zero $(\mathrm{PN})$ to three (3PN) (as exemplified below). The accented syllable in all sentences is the CVC syllable /man/.

OPN: Man is an animal.

1PN: A man from the garage called.

2PN: There's a man from the garage here.

3PN: There was a man from the garage here.

Data for two speakers from each dialect (age ranging from 16 to 28) are reported here. Speakers from Donegal and Dublin were recorded in the semi-anechoing recording booth in the Phonetics Laboratory at Trinity College. The other two speakers were recorded in a quiet room in a cultural institution in Drogheda using a digital recorder, ZOOM Handy Recorder H4. Each speaker read five randomised repetitions of the data. Sentences were prompted separately on a computer screen. This gives 80 sentences per dialect: 2 speakers $\mathrm{x} 2$ positions $\mathrm{x}$ 4 sentences $x 5$ repetitions. Data was analysed using the PRAAT software [17]. Sentences unsuitable for analysis were excluded from the data.

\subsection{Measurements}

The averaged durations of the controlled unstressed syllables and of the accented syllables were calculated. The following measurements were taken, as shown in Figure 2:

- durH: the distance from the beginning of the accented syllable to the peak position $(\mathrm{H})$.

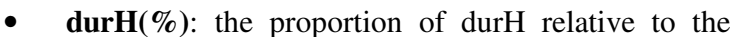
duration of the accented syllable.

- durL: the distance from the beginning of the accented syllable to the $\mathrm{L}$ position of the pitch accent $\left(\mathrm{L}^{*} \mathrm{H}\right)$ in the Donegal data.

- durL(\%): the proportion of durL relative to the duration of the accented syllable in the Donegal data.

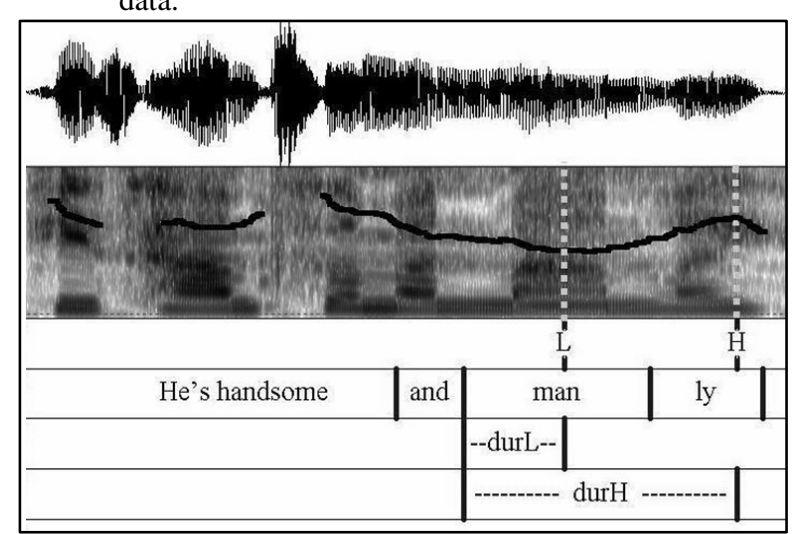

Figure 2: An illustration of durL and durH measurements in the sentence 'He's handsome and manly.' of the N1 condition in Donegal English.
In this study peak alignment is presented as a percentage of the peak duration from the beginning of the accented syllable to its location relative to the duration of the accented syllable $(\operatorname{durH}(\%))$. This is the value used in the statistical tests.

In the data examined, the $\mathrm{L}^{*}$ of $\mathrm{L}^{*} \mathrm{H}$ in both pre-nuclear and nuclear rises, was often realised as a plateau rather than as a turning point. In these cases it was decided to take measurements for time values of $\mathrm{L}$ at the middle of the plateau. In cases where the peak position was not clear due to perturbations by adjacent voiceless consonants, the peak point was selected manually.

\section{Results}

Figures 3-5 show the peak alignment for each dialect in both $\mathrm{PN}$ and $\mathrm{N}$ positions. The upward pointing arrows in the figures indicate the location of the $\mathrm{H}$ peak. Downward pointing arrows represent the location of $\mathrm{L}$ in $\mathrm{L} * \mathrm{H}$ of Donegal English. The percentages shown beneath the arrows represent $\operatorname{durH}(\%)$ values and the durL $(\%)$ values.

Results suggest that the peak position is fairly stable in pre-nuclear and nuclear conditions for Dublin and Drogheda. Exceptions are the OPN and N0 conditions, particularly in Dublin English. Donegal English shows drifting peaks in both the $\mathrm{PN}$ and $\mathrm{N}$ conditions.

\subsection{Dublin English}

Figure $3 \mathrm{a}$ shows that the peak is fairly stable in $1 \mathrm{PN}, 2 \mathrm{PN}$, $3 \mathrm{PN}$ conditions (average duration of durH in these conditions is $201 \mathrm{~ms}$ ). A 1-way ANOVA test run on all PN conditions showed that the durH $(\%)$ differences were significant. When the OPN condition was excluded, the test showed that the values were not significant $F(2,27)=1.19 p=0.321)$. Figure $3 \mathrm{~b}$ shows that the peak alignment is fairly stable in N1, N2, N3 conditions (average of durH in these is $194 \mathrm{~ms}$ ). A 1-way ANOVA showed that for all $\mathrm{N}$ conditions the differences in $\operatorname{durH}(\%)$ was significant. Again, when the N0 values were excluded, the test showed that the differences were not significant $(\mathrm{F}(2,28)=3.27, \mathrm{p}=0.054)$.

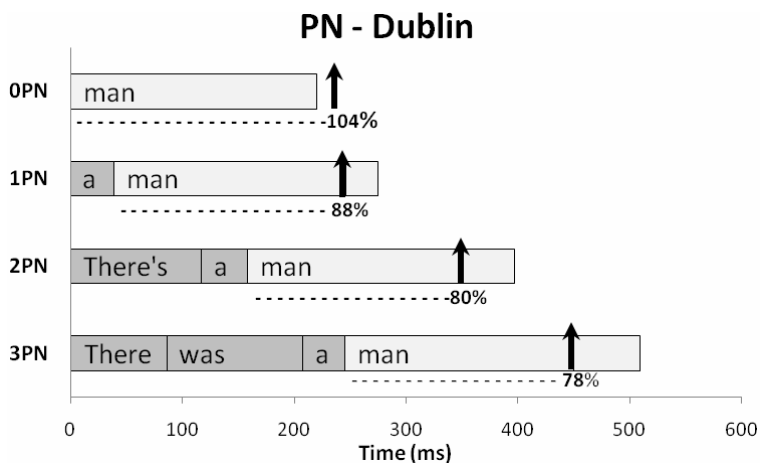

Figure 3a: Peak position and durH(\%) shown in $P N$ conditions for Dublin English. 


\section{N- Dublin}

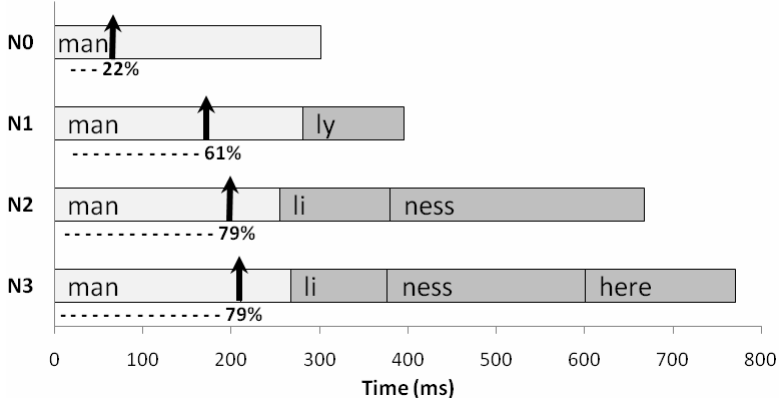

Figure 3b: Peak position and durH(\%) shown in $N$ conditions for Dublin English.

\subsection{Drogheda English}

Figure 4a shows the alignment of the peak in the PN position. The peak placement is fairly stable in the PN conditions (average of durH is $128 \mathrm{~ms}$ ). A 1-way ANOVA showed that for all $\mathrm{PN}$ conditions the differences in $\operatorname{durH}(\%)$ were not significant $(F(3,24)=0.27, p=0.844)$. Figure $4 b$ shows that $\mathrm{N} 1, \mathrm{~N} 2, \mathrm{~N} 3$ conditions are also fairly stable (average duration of durH in these conditions is $112.5 \mathrm{~ms}$ ). A 1-way ANOVA test run on all $\mathrm{N}$ conditions showed that $\operatorname{durH}(\%)$ differences were significant. When the N0 condition was excluded, the same test showed that the differences were not significant. ( $F$ $(2,25)=0.28, \mathrm{p}=0.382)$.

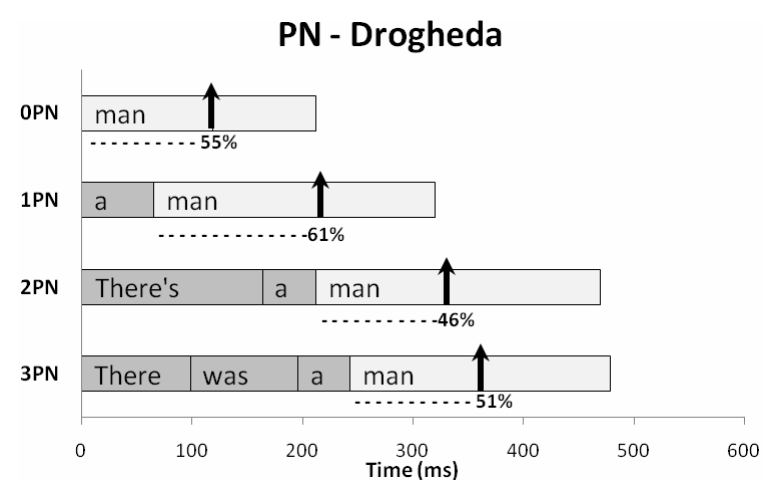

Figure 4a: Peak position and durH(\%) shown in PN conditions for Drogheda English.

\section{N- Drogheda}

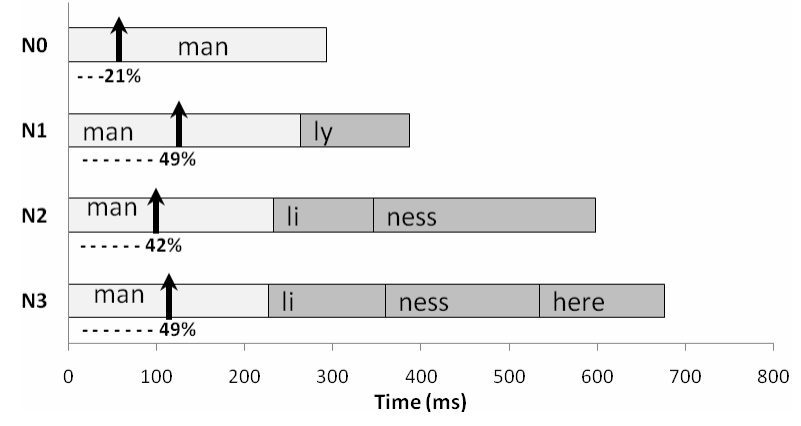

Figure 4b: Peak position and durH(\%) shown in $N$ conditions for Drogheda English.

\subsection{Donegal English}

Figure $5 \mathrm{a}$ shows that the peak drifts rightwards as the number of unstressed syllables before the accented syllable increases. The average durations of durH in $0 \mathrm{PN}, 1 \mathrm{PN}, 2 \mathrm{PN}$, and $3 \mathrm{PN}$ are $283 \mathrm{~ms}, 314 \mathrm{~ms}, 304 \mathrm{~ms}$, and $423 \mathrm{~ms}$, respectively. A 1way ANOVA showed that for all $\mathrm{PN}$ conditions the differences in $\operatorname{durH}(\%)$ were significant $(\mathrm{F}(3,36)=5.53, \mathrm{p}=$ $0.003)$. Tukey's pairwise comparisons indicate that $1 \mathrm{PN}$ and $2 \mathrm{PN}$ values were not significantly different. Figure $5 \mathrm{~b}$ shows that the peak alignment in all $\mathrm{N}$ conditions increases with the number of following unstressed syllables. The average durations of durH in $\mathrm{N} 0, \mathrm{~N} 1, \mathrm{~N} 2$, and $\mathrm{N} 3$ are $333 \mathrm{~ms}, 395 \mathrm{~ms}$, $460 \mathrm{~ms}$, and $589 \mathrm{~ms}$, respectively. A 1-way ANOVA test run on all $\mathrm{N}$ conditions showed that the differences in $\operatorname{durH}(\%)$ were significant $(\mathrm{F}(3,37)=37.32, \mathrm{p}=0.000)$. In both $\mathrm{PN}$ and $\mathrm{N}$ conditions, the alignment of $\mathrm{L}^{*}$ lies within the accented syllable.

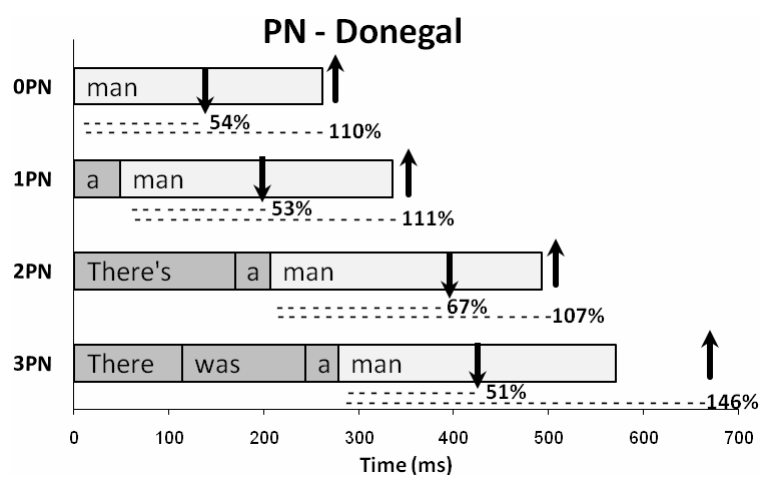

Figure 5a: Valley and peak locations of the $L^{*} H$ pitch accent, durL(\%), and durH(\%) shown in PN conditions for Donegal English.

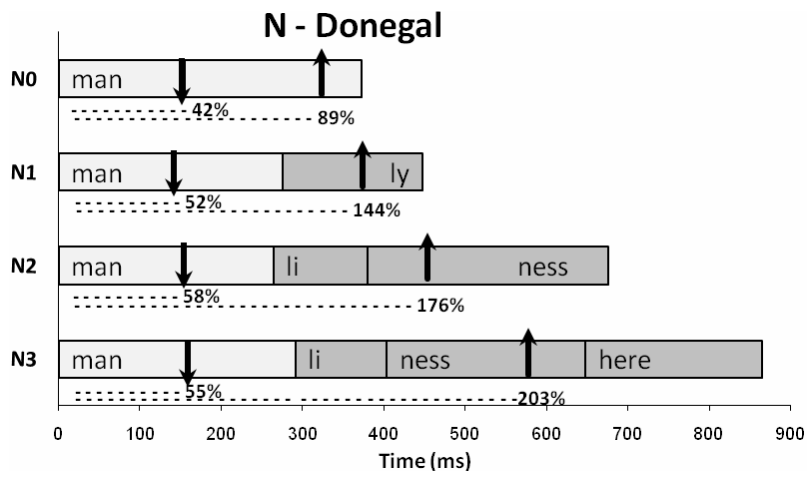

Figure 5b: Valley and peak locations of $L^{*} H$ pitch accent, durL (\%), and durH(\%) shown in $N$ conditions for Donegal English.

\section{Discussion}

In Dublin English, the peak seems to be fixed within the accented syllable regardless of the number of unstressed syllables preceding the pre-nuclear or following the nuclear accent, except with the OPN and N0 conditions. We would suggest that the variability seen in OPN and NO reflects a 
production constraint where the later (or earlier) peak is required to allow the peak (or fall) to be realised. Closer observation of the Dublin data suggests that the peak is fixed at the VC boundary of the accented syllable in both PN and $\mathrm{N}$ conditions. Again, the exceptions are OPN and N0 conditions.

In Drogheda English the alignment of the location of the peak is also fixed within the accented syllable regardless of the number of unstressed syllables preceding the pre-nuclear or following the nuclear accent. Closer observation suggests that the peak is aligned near the end of the vowel in the accented syllable in both PN and N conditions. Similarly the 0PN and the N0 conditions are controlled by time pressure, although not as clearly as in the Dublin English data.

In Donegal English the location of the valley $\left(\mathrm{L}^{*}\right)$ in the pitch accent in both PN and $\mathrm{N}$ conditions is fixed regardless of the number of unstressed syllables preceding the pre-nuclear or following the nuclear accent. The valley of the pitch tone $\mathrm{L} * \mathrm{H}$ in $\mathrm{PN}$ and $\mathrm{N}$ conditions usually falls within the vowel of the accented syllable. In PN conditions, results suggest that the peak drifts rightwards as the number of unaccented syllables in the anacrusis increases. Statistical tests, however, show that $1 \mathrm{PN}$ and $2 \mathrm{PN}$ conditions are not significantly different. We propose that this is due to inter-speaker variation and the limited number of speakers per dialect in this pilot study. In $\mathrm{N}$ conditions the peak clearly drifts rightwards with the increase in the number of following unstressed syllables. The trailing peak $(\mathrm{H})$ always falls on the first or second unstressed syllable following the accented one. The distance between $\mathrm{L}^{*}$ and $\mathrm{H}$ in N0, N1, N2 and N3 is $179 \mathrm{~ms}, 254 \mathrm{~ms}, 307 \mathrm{~ms}$, and $430 \mathrm{~ms}$, respectively.

Another observation is the cross-dialect difference in the fixed peak position of Dublin and Drogheda English. Results show that the peak in Drogheda English is always earlier than that in Dublin English in both nuclear and pre-nuclear conditions. Similar differences have been reported for Scottish Standard English, RP, and Dutch [2].

Furthermore, similar to previous studies $[1,4]$ the $\mathrm{H}^{*}$ alignment in nuclear conditions is always earlier than in prenuclear conditions.

Cross-dialectal comparison suggests that the southern varieties of HE are not only similar in intonational patterns, but can share fine timing of peak alignment behaviour, as the data from Drogheda and Dublin English shows. Although Donegal English has a different tonal pattern, the main tonal target (in this case $\mathrm{L}^{*}$ ) has a fixed alignment. The valley always lies within the accented syllable regardless of the number of unstressed syllables preceding the PN or following the $\mathrm{N}$ accent.

\section{Conclusions}

The present paper adds to the body of intonational studies on alignment in varieties of the same language. The three Hiberno-English dialects investigated show fixed alignment of $\mathrm{H}^{*}$ (Dublin and Drogheda) and L* (Donegal) in N and PN conditions. Dublin English peak alignment seems to be fixed at the VC boundary. In Drogheda English the peak is somewhat earlier, near the end of the vowel of the accented syllable. The exceptions to the fixed peak alignment are the immediate pre-boundary and post-boundary accented syllables, cases N0 and OPN respectively. This is likely to be caused by time pressure to realize the target tone immediately before the boundary or after it. The alignment of $\mathrm{H}^{*}$ is always earlier in nuclear accents than in pre-nuclear ones. These findings are reminiscent of peak alignment behaviour in Irish dialects. In Donegal English the peak drift of the trailing $\mathrm{H}$ increases proportionally with the number of unstressed syllables before the pre-nuclear or after the nuclear accent. Mayo Irish and Donegal Irish manifest peak drift conditioned by the number of unstressed syllables before the pre-nuclear or after the nuclear accent $[4,5]$. Cois Fharraige, on the other hand, is similar to Dublin English in the position of the fixed peak at the consonant boundary of the accented syllable [5].

The syllable structure controlled in this study is a checked CVC syllable. Future research will consider investigating syllable structure influence on peak alignment in the analysed dialects. An open CV syllable /ma/ followed by an intervocalic consonant (manager) will be analysed and compared to the present CVC /man/ data.

The present investigation is a pilot study, with a limited number of speakers per dialect. We do not propose that results are definite, but they shed light on fine-detailed prosodic differences across varieties of Hiberno-English.

\section{References}

[1] Schepman, A., Lickley, R., and Ladd, D.R., "Effects of vowel length and "right context" on the alignment of Dutch nuclear accents," Journal of Phonetics, 35, 2006, pp. 1-28.

[2] Ladd, D.R., Schepman, L., White, L., Quarmby, L.M., and Stackhouse, R., "Structural and dialectal effects on pitch peak alignment in two varieties of British English," Journal of Phonetics, 2009, doi:10.1016/j.wocn.2008.11.001.

[3] Ladd, D.R., Mennen, I., and Schepman, A., "Phonological conditioning of peak alignment in rising pitch accents in Dutch," Journal of the Acoustical Society of America, 107, 2000, pp. 2685-2696.

[4] Dalton, M. and Ní Chasaide, A., "Tonal Alignment in Irish Dialects," Language and Speech, 48, 2005, pp. 441-464.

[5] Ní Chasaide, A, Dalton, M., "Dialect Alignment Signatures," Proc. of Speech Prosody 2006, Dresden, 2006.

[6] Barry, M.V. "The southern boundaries of northern HibernoEnglish speech," in Barry, M.V. [Ed] Aspects of English dialects In Ireland: papers arising from the tape-recorded survey of Hiberno-English speech.Vol.1.Belfast: The Institute of Irish Studies, The Queen's University of Belfast, $1981 \mathrm{~b}$.

[7] Adams, G., "An introduction to the study of Ulster dialects," Proceedings of the Royal Irish Academy. 52. C, 1948, pp.126.

[8] Hickey, R., Irish English. Cambridge: Cambridge University Press, 2007.

[9] Grabe, E., "Variation adds to prosodic typology," in Bel, B. and Marlin, I. [Eds] Proceedings of the Speech Prosody 2002 Conference, 11-13 April 2002, Aix-en-Provence: Laboratoire Parole et Langage, 2002, pp.127-132.

[10] Rahilly, J., "Aspects of prosody in Hiberno-English: the case of Belfast," in Kallen, J. [Ed\} Varieties of English around the world: focus on Ireland. Amsterdam: John Benjamins Publishing Company, 1997.

[11] O'Connor, R., "A study of the intonation of a west Cork dialect of English," MPhil. Dissertation, Trinity College Dublin, 2005.

[12] Sullivan, J. N., "Tonal alignment studies in three dialects of Hiberno-English," MLitt. Dissertation, University College Dublin, 2006.

[13] Dorn, A., "An Intonational Analysis of Donegal English," MPhil. Dissertation, Trinity College Dublin, 2006.

[14] Bliss, A., "English in the south of Ireland," in Trudgill, P. [Ed.] Language in the British Isles. Cambridge: CUP, 1984.

[15] Henry, P. L., Anglo-Irish dialect of north Roscommon: Phonology, accidence, syntax. Zurich: Ashman and Scheller Ltd, 1957.

[16] Wells, J. C., Accents of English. rpt. 1996 Cambridge: Cambridge University Press, 1982.

[17] Boersma, P., and Weenik, D., "Praat: doing phonetics by computer", Version 5.1, 2009. www.praat.org/ 